\title{
Cycle per Minute
}

National Cancer Institute

\section{Source}

National Cancer Institute. Cycle per Minute. NCI Thesaurus. Code C71176.

A unit of frequency equal to the frequency at which one complete execution of a

periodically repeated phenomenon, alternation, event, or sequence of events occurs per unit of time equal to one minute. 